\title{
Utilizing the Ambulatory Glucose Profile to Standardize and Implement Continuous Glucose Monitoring in Clinical Practice
}

\author{
Mary L. Johnson, BS, RN, CDE, Thomas W. Martens, MD, ${ }^{2}$ Amy B. Criego, MD, MS, ${ }^{3}$ \\ Anders L. Carlson, MD, ${ }^{4}$ Gregg D. Simonson, PhD, and Richard M. Bergenstal, MD ${ }^{1}$
}

\begin{abstract}
Use of continuous glucose monitoring (CGM) is recognized as a valuable component of diabetes selfmanagement and is increasingly considered a standard of care for individuals with diabetes who are treated with intensive insulin therapy. As the clinical use of CGM technology expands, consistent and standardized glycemic metrics and glucose profile visualization have become increasingly important. A common set of CGM metrics has been proposed by an international expert panel in 2017, including standard definitions of time in ranges, glucose variability, and adequacy of data collection. We describe the core CGM metrics, as well as the standardized glucose profile format consolidating 2 weeks of CGM measurements, referred to as the ambulatory glucose profile (AGP), which was also recommended by the CGM expert panel. We present an updated AGP report featuring the core CGM metrics and a visualization of glucose patterns that need clinical attention. New tools for use by clinicians and patients to interpret AGP data are reviewed. Strategies based on the authors' experience in implementing CGM technology across the clinical care spectrum are highlighted.
\end{abstract}

Keywords: Continuous glucose monitoring, Ambulatory glucose profile, Diabetes technology, Glucose monitoring.

\section{Introduction}

$\mathbf{F}$ OR PEOPLE LIVING WITH DIABETES, management decisions to minimize hypoglycemia and hyperglycemia require constant attention. During the past decade, there has been a growing shift away from traditional self-monitoring of blood glucose (SMBG) using fingerstick capillary glucose checks to use of continuous glucose monitoring (CGM) in type 1 diabetes (T1D) and more recently, type 2 diabetes (T2D).

The emergence of CGM has expanded our ability to create a more complete picture of patients' actual glucose status throughout the day and night. Unlike SMBG, real-time CGM devices present information about the current glucose level, glucose trends, and rate of change arrows, which indicate the direction and velocity of changing glucose. Users are then able to respond immediately to mitigate or prevent acute hypoglycemia and hyperglycemia. Recent consensus reports provide clinical guidance for using trend arrow data with the Dexcom and FreeStyle Libre systems. ${ }^{1,2}$

In addition, retrospective glucose trend data can be downloaded and reviewed, enabling patients and their health care team to identify glycemic patterns that may indicate the need for therapy adjustments and/or lifestyle and behavior changes.

The clinical efficacy and benefits of CGM use have been demonstrated in numerous studies of individuals with T1D and a fewer number of studies of individuals with T2D treated with multiple daily injections (MDI) or insulin pumps. ${ }^{3-11}$ Glycemic benefits have also been shown when CGM is utilized as an integrated component of sensoraugmented insulin pumps with predictive low glucose suspend functionality ${ }^{12,13}$ and automated insulin delivery systems (hybrid closed loop systems). ${ }^{14,15}$

\footnotetext{
${ }^{1}$ International Diabetes Center at Park Nicollet, Minneapolis, Minnesota.

${ }^{2}$ Park Nicollet Clinic, International Diabetes Center at Park Nicollet, Minneapolis, Minnesota.

${ }^{3}$ Department of Pediatric Endocrinology, Park Nicollet Clinic, International Diabetes Center at Park Nicollet, Minneapolis, Minnesota.

${ }^{4}$ Health Partners, International Diabetes Center at Park Nicollet, Minneapolis, Minnesota.
} 
In light of these findings, use of CGM is recommended by expert clinician consensus and national and international medical organizations for individuals with diabetes who are treated with intensive insulin therapy and/or those at risk for hypoglycemia ${ }^{16-18}$ and it should be considered for most patients who want to improve percentage of time spent in target glucose range while minimizing hypoglycemia. However, utilization of CGM data by clinicians has remained suboptimal. Time constraints, potential disruption of workflow associated with data downloading, and perceived complexity of data interpretation often impact optimal use in clinical practice. ${ }^{19}$

The ambulatory glucose profile (AGP) is a standardized, single-page glucose report designed to simplify analysis and interpretation of downloaded CGM data. This article discusses the development, key metrics, and utility of the AGP for use in clinical practice and research settings.

\section{Rationale for Standardization}

Achieving desired clinical outcomes from CGM use requires the ability to interpret the collected data and act upon it appropriately. Meeting these criteria involves two distinct components: (1) common metrics for assessment of glycemic status; and (2) straightforward statistical and graphic visualization of the glucose data.

\section{Development of common metrics}

Measurement of glycated hemoglobin (HbAlc) has long been recognized as the "gold standard" for evaluating glycemic management. However, while HbAlc provides a surrogate marker for the development of long-term complications, it has several limitations. Because HbA1c is only a measure of the average glucose over 2-3 months and primarily a measure of hyperglycemia, it does not reflect glucose variability or hypoglycemia. It fails to identify the magnitude and frequency of intraday and interday glucose fluctuations, which can indicate patterns of problematic hypoglycemia and hyperglycemia, which would benefit from therapy and/or lifestyle modifications.

Moreover, $\mathrm{HbA} 1 \mathrm{c}$ is an unreliable measure in multiple settings; certain conditions such as anemia ${ }^{20}$ hemoglobinopathies, ${ }^{21}$ iron deficiency, ${ }^{22}$ and pregnancy ${ }^{23}$ can confound test results. Even when none of these conditions can be identified, the HbA1c can at times fail to accurately reflect mean glucose. ${ }^{24}$ Although CGM provides the means to move beyond $\mathrm{HbAlc}$ as the sole marker of glycemic management, standardized measures of glycemic assessment based on CGM data have, until recently, been lacking.

In February 2017, the Advanced Technologies and Treatments for Diabetes (ATTD) Congress convened an international panel of expert physicians and researchers to define specific metrics for assessing CGM data. ${ }^{18}$ Items the authors consider to be core CGM measures from this consensus document are presented in Table 1. Among the key metrics identified were time in specified ranges, glycemic variability, and adequate data collection period.

Times in ranges. Times in ranges refer to the time spent within hypoglycemia ranges, in target range, and in hyperglycemic ranges. Traditionally, the goal of diabetes selfmanagement is to achieve and maintain glucose levels within each patient's individualized target range. We now know that time in target range (TIR) $(70-180 \mathrm{mg} / \mathrm{dL})$ alone is not an

Table 1. Core Continuous Glucose Monitoring Metrics

\begin{tabular}{|c|c|}
\hline Measures & Values \\
\hline $\begin{array}{l}\text { Mean glucose } \\
\text { GMI (previously eA1c) }\end{array}$ & $\begin{array}{l}\text { Calculated from all CGM values } \\
\text { Derived from CGM mean glucose }\end{array}$ \\
\hline $\begin{array}{l}\text { Percentage of time in hyperglycemic ranges }(\mathrm{mg} / \mathrm{dL} / \mathrm{mmol} / \mathrm{L}) \\
\text { Very high (Level 2) } \\
\text { High (Level 1) }\end{array}$ & $\begin{array}{c}>250 />13.9 \\
181-250 / 10.1-13.9\end{array}$ \\
\hline $\begin{array}{l}\text { Percentage of TIR }(\mathrm{mg} / \mathrm{dL} / \mathrm{mmol} / \mathrm{L}) \\
\text { Percentage of time in hypoglycemic ranges, } \mathrm{mg} / \mathrm{dL}(\mathrm{mmol} / \mathrm{L})\end{array}$ & 70-180/3.9-10.0 \\
\hline $\begin{array}{l}\text { Low (Level 1) } \\
\text { Very low (Level 2) }\end{array}$ & $\begin{array}{c}54-69 / 3.0-3.8 \\
<54 /<3.0\end{array}$ \\
\hline $\mathrm{GV}$ & \\
\hline $\begin{array}{l}\text { Stable } \\
\text { Unstable }\end{array}$ & $\begin{array}{l}\% \mathrm{CV} \leq 36 \\
\% \mathrm{CV}>36\end{array}$ \\
\hline $\begin{array}{l}\text { Three time periods for evaluation } \\
\text { Sleep } \\
\text { Wake } \\
24 \mathrm{~h}\end{array}$ & $\begin{array}{l}12 \mathrm{AM}-5: 59 \text { AM } \\
6 \text { AM-11:59 PM } \\
12 \mathrm{AM}-12 \text { AM }\end{array}$ \\
\hline $\begin{array}{l}\text { Recommended data sufficiency } \\
\text { Collection period } \\
\text { Percentage of expected CGM readings (minimum percentage) }\end{array}$ & $\begin{array}{c}14 \text { days } \\
70 \% \text { (10 of } 14 \text { days })\end{array}$ \\
\hline Standardized CGM report & AGP \\
\hline
\end{tabular}

${ }^{\mathrm{a}} \mathrm{GMI}(\%)=3.31+0.02392 \times[$ mean glucose in $\mathrm{mg} / \mathrm{dL}] .{ }^{23,43} \mathrm{Jaeb}$ Center for Health Research. HbA1c estimator [Internet]. Available from https://www.jaeb.org/gmi (accessed April 22, 2019).

AGP, ambulatory glucose profile; CGM, continuous glucose monitoring; \%CV, percent coefficient of variation; eA1c, estimated HbA1c; GMI, glucose management indicator; GV, glucose variability; HbA1c, glycated hemoglobin; TIR, time in target range. 
adequate measure of overall glycemic control; it is also necessary to quantitate the time spent below and above target range, using specified severity thresholds for each level. ${ }^{25}$

With consensus on the definition for TIR, ${ }^{18}$ the strong correlation of TIR with microvascular complications has been published. ${ }^{26,27}$ There is also evidence to support the clinical impact of the number of events and time spent $<54 \mathrm{mg} / \mathrm{dL}(<3.0 \mathrm{mmol} / \mathrm{L}){ }^{28-32}$ TIR and time spent in hypoglycemia have also been a recent focus for outcome measures for efficacy claims in clinical trials.

A recent study by Lu et al. demonstrated a significant association between time in range and prevalence of diabetic retinopathy in a cohort of 3262 individuals with T2D. ${ }^{26}$ Beck et al. found similar associations between percentage of time spent within and above target range (based on seven-point profile SMBG profiles) and the risk for diabetic retinopathy and microalbuminuria outcomes among participants in the Diabetes Control and Complications Trial (DCCT) ${ }^{27}$ Beck et al. have also presented data based on post hoc analysis of the same DCCT data set linking biochemical glucose of $<70$ and $<54 \mathrm{mg} / \mathrm{dL}$ with "increased risk for severe hypoglycemia." 33 These findings strongly suggest that time spent in specified ranges is a valuable measure of glycemic control and an acceptable endpoint for clinical research.

One approach to formulating suggested goals for the percent of time spent in each of the specific glucose ranges, is to base them on what is achievable, on average, using the most advanced automated insulin delivery technology commercially available today. When the $670 \mathrm{G}$ pivotal trial data was reanalyzed using the currently recommended TIR categories, it showed $0.8 \%$ time spent very low $(<54 \mathrm{mg} / \mathrm{dL}[<3.0$ $\mathrm{mmol} / \mathrm{L}]) ; 3.0 \%$ time spent low $(<70 \mathrm{mg} / \mathrm{dL}[<3.9 \mathrm{mmol} / \mathrm{L}])$; $72.4 \%$ time within target range $(70-180 \mathrm{mg} / \mathrm{dL}$ (3.9$10 \mathrm{mmol} / \mathrm{L}]) ; 24.5 \%$ time high (>180 $\mathrm{mg} / \mathrm{dL}[>10 \mathrm{mmol} / \mathrm{L}]$ ); and $5.6 \%$ time very high $(>250 \mathrm{mg} / \mathrm{dL}[>13.9 \mathrm{mmol} / \mathrm{L}]){ }^{34}$

Glycemic variability. Extreme excursions in blood glucose levels can increase average glucose levels and often result in hyperglycemic and/or hypoglycemic events. However, intensifying therapy to lower average glucose levels by relying on HbAlc alone may result in more time spent in hypoglycemia. ${ }^{35-37}$ An increased risk of hypoglycemia has been associated with an increase in glucose variability ${ }^{38}$ as reported in several clinical trials. ${ }^{39-40}$ Moreover, a number of recent studies have shown strong correlations of TIR $(70-180 \mathrm{mg} / \mathrm{dL}$ [3.9-10.0 mmol/L]) with diabetes complications. ${ }^{26,27}$

Unlike HbAlc, use of CGM allows for the direct observation of glycemic excursions and the ability to quantify glucose variability. For example, an analysis of CGM data in comparison to blood glucose data showed a strong correlation between time spent in hypoglycemia and glycemic variability indices (e.g., coefficient of variation [CV], low blood glucose index), but not with HbA1c. ${ }^{41}$

Thus, characterization of glycemic variability using standard metrics such as CV may be helpful in optimizing glucose control by reducing the frequency and the extent of both high and low glucose excursions without increasing the risk for hypoglycemia. According to the consensus recommendations, relying on published outcome data, the suggested cutpoint for $\mathrm{CV}$ was $36 \%$; $\leq 36 \%$ is considered a stable glucose profile and $>36 \%$ is considered an unstable glucose profile. ${ }^{42}$ We favor the use of $\mathrm{CV}$ over standard deviation (SD) to assess glucose variability as the $\mathrm{CV}$ calculation accounts for an individual's mean glucose, which SD does not. Unlike CV, SD decreases as mean glucose decreases, introducing a component of relativity such that decreases in SD do not always reflect a true decrease in variability. The $\mathrm{CV}$ can be compared across time irrespective of changes in mean glucose for a given patient, which allows clinicians to follow true glucose variability from visit to visit.

Adequacy of collected data. Retrospective analysis of CGM data visualizes patterns of hypoglycemia, hyperglycemia, and glycemic variability quantifying time spent in low, target, and high ranges. It is important to note, however, that an adequate number of CGM readings is needed to determine the clinical significance of this information.

Recent studies have shown that 14 days of CGM data correlate strongly with 3 months of data for mean glucose, time in ranges, and hyperglycemia metrics. ${ }^{43,44}$ The correlation is lower for hypoglycemia and glycemic variability; however, these measures do not significantly increase with longer sampling periods. ${ }^{44}$ Based on these findings, it is recommended that if a 14-day interval is being analyzed, there should be at least 10 days of CGM data available to confidently evaluate the data for research use or clinical management. ${ }^{18}$

\section{Glucose management indicator}

In addition to the other metrics discussed, it has been shown that 14 days of CGM data can be used to estimate $\mathrm{HbA1c}$ if there have not been recent meaningful changes in diabetes management or other acute factors affecting glycemic ranges. ${ }^{44}$ Although the estimated HbA1c (eA1C) provides a close approximation of a laboratory-measured HbA1c in some patients, it may be higher or lower than actual HbAlc in others. ${ }^{24}$ As demonstrated by Beck et al., a laboratory-measured $\mathrm{HbA} 1 \mathrm{c}$ of $8.0 \%$ could be associated with a CGM-measured mean glucose concentration as low as $155 \mathrm{mg} / \mathrm{dL}$ or as high as $218 \mathrm{mg} / \mathrm{dL}$, which substantially overlaps the confidence intervals of HbAlc of 7.0\% (128$190 \mathrm{mg} / \mathrm{dL})$ and $\mathrm{HbA} 1 \mathrm{c}$ of $9.0 \%(182-249 \mathrm{mg} / \mathrm{dL}){ }^{24}$

Because the potential discrepancy between eA1C and actual $\mathrm{HbA1c}$ values can be confusing for patients and clinicians, it was recently proposed that changing the name from "eA1C" to "Glucose Management Indicator (GMI)" would convey that this measure is derived from glucose values obtained during the CGM wear period. Laboratory measured HbA1c may differ from GMI due to differences in red blood cell lifespan, hemoglobinopathies and factors that may have affected glucose control during the CGM measurement period such as illness, significant change in diet or exercise habits, or certain medications such as corticosteroids. The GMI (calculated from the CGM mean glucose) is an estimate of the HbAlc based on CGM glucose levels the individual is experiencing over several weeks and can be a helpful management tool to use when setting individualized $\mathrm{HbAlc}$ goals or making therapy adjustments. ${ }^{45}$

If the GMI is considerably different than the laboratory HbAlc, it may be important to take this difference into account when setting an HbA1c goal. For instance, if the GMI estimates the $\mathrm{HbA} 1 \mathrm{c}$ to be $7.4 \%$ and the laboratory HbA1c is $8 \%$, one would need to be careful not to lower the glucose too aggressively since the GMI indicates this individual's actual glucose levels may already be lower than one would typically associate with the laboratory $\mathrm{HbA1c}$. 
The American Diabetes Association (ADA) has commented that the GMI terminology is an important step for the proper use of CGM mean glucose data and that GMI inclusion in diabetes management software may offer added insights into glycemic control. ${ }^{46}$

\section{Standardized visualization of the glucose data}

In 2013, a panel of expert clinicians published consensus recommendations for use of the AGP to visualize glucose data. ${ }^{47}$ This recommendation was later endorsed in an international consensus conference convened in Paris in $2017^{18}$ and is now referenced as an example of a standardized CGM report in the ADA 2019 Standards of Care (page 75) ${ }^{16}$ and an update to the AACE consensus on use of CGM. ${ }^{48}$ Most of the CGM device manufacturers now include variations of the AGP format in their download software. ${ }^{49}$

\section{Ambulatory Glucose Profile}

The first AGP graph was created by Mazze et al. ${ }^{50}$ Subsequent versions were developed at the International Diabetes Center (IDC), including the current version in Figure 1. The AGP is a single-page report, with standardized statistical and graphic information that visually represents time in standardized glycemic ranges, glucose variability, and glycemic exposure over a defined period of time using downloaded CGM or SMBG data. ${ }^{47}$ The one page standard AGP report also includes the daily glucose views or a calendar format of the daily readings that make up the AGP summary glucose profile. The AGP reduces clinician and health care team burden by making glucose data easily comparable across all devices.

\section{CGM report: $A G P$}

The default screen presents a standardized "dashboard" that displays the most relevant statistical and graphical information that allows clinicians and patients to quickly assess patients' glycemic status and make meaningful, clinical decisions. As shown in Figure 1, the report is organized into three major components: (1) Glucose Statistics and Time in Range; (2) CGM Glucose Profile (standard/modal day, referred to as AGP); and (3) Daily Glucose Profiles.

Information presented in the Glucose Statistics presents statistical data relevant to adequacy of data set and overall glycemic management, including number and percentage of days CGM was active; average glucose and GMI; and glycemic variability using \%CV calculations. The color-coded stacked bar graph, first introduced by Rodbard, ${ }^{51}$ reports the percentage of time spent within designated glucose ranges: target range 70-180 mg/dL; low (level 1), 54-69 mg/dL; very low (level 2), $<54 \mathrm{mg} / \mathrm{dL}$; high (level 1), 181-250 mg/dL; and very high (level 2), >250 mg/dL.

The AGP combines all daily glucose profiles from the CGM into a single, 24-h "modal" day, in which all collected data over multiple days are collapsed and plotted according to time (without regard to date) as if they occurred over $24 \mathrm{~h}$. This presentation enables clinicians to quickly identify the time(s) of day when glucose is most consistently low or high and when the most variability is occurring. Curves representing the median (50th), 25th and 75th (interquartile range [IQR]), and 5th and 95th frequency percentiles define the overall 24-h glucose profile. IQR is the range within which $50 \%$ of the glucose values fall represented by the 25 th and 75 th percentile trend lines. The IQR provides an easy visualization of glucose variability, whereas the $\% \mathrm{CV}$ is a useful measure to assess glucose stability and changes in variability over time.

Earlier versions of the AGP identified the 10th and 90th frequency percentiles; however, the most recent AGP profile (presented here) has moved to the 5th and 95th frequency percentiles to better identify infrequent, yet, significant hypoglycemia, which is less easily visualized when a $10 \%$ frequency percentile trend line is used. There has been a previous excellent discussion of the potential value of using different glucose percentiles. ${ }^{52}$

The Daily Glucose Profiles present thumbnail or calendar view profiles of the 24-h pattern for each day that is included in the overall profile. This allows for comparison of patterns on specific days (e.g., weekend vs. weekday) and permits a more comprehensive discussion with patients regarding special circumstances that may be responsible for extremes or fluctuations in glucose readings. Clicking a thumbnail will enlarge it to a full size 1 day AGP with corresponding glucose metrics for that day. Time spent below range and above range is also designated by color changes, red and yellow, respectively.

\section{Training in CGM data interpretation}

The AGP provides an effective way to consolidate and display CGM data, providing important insights into several indicators of glycemic management. The ability to quickly assess overall glycemia and identify patterns of concern not only facilitates more informed therapy decision-making but also helps patients better understand interactions between their medications, meals, and exercise.

While the AGP was quickly accepted by both physicians and patients across multiple care settings, there was a need for tools for both clinicians as well as patients to optimize interpretation of AGP-generated data. To address this need, IDC created a "9 Step" interpretation plan:

1. Make sure there are adequate data for decision-making (ideally 14 days, at least 10 days).

2. If possible, mark directly on a printed copy of the AGP:

- Type and duration of diabetes, age, weight (kg), and, if on insulin, daily dose (units/kg).

- Usual times for waking (W), breakfast (B), lunch (L), dinner (D), and bedtime (BT).

- Medication time and doses directly under the curve at the time usually taken. (This is a good time to emphasize how critical it is to take bolus insulin before meals.)

- If there is a consistent time of exercise or snacking.

3. Once the report is "marked up," ask the patient to briefly describe and explain what he or she sees and why. Patients often provide honest, helpful insights to explain the glucose patterns.

4. Look for patterns of low glucose readings.

- Remember, if the $5 \%$ lower line is touching the $70 \mathrm{mg} / \mathrm{dL}$ target line during a particular period of the day, $5 \%$ of all glucose values are $<70 \mathrm{mg} / \mathrm{dL}$ at that time. Consider taking some action. If the $25 \%$ line is touching or below the $70 \mathrm{mg} / \mathrm{dL}$ target line or the $5 \%$ line reaches $54 \mathrm{mg} / \mathrm{dL}$, immediate action is required. 


\section{AGP Report}

Name

MRN

GLUCOSE STATISTICS

26 Feb 2019-10 Mar 2019

$\%$ Time CGM is Active

Average Glucose

Glucose Management Indicator (GMI)

Glucose Variability

Defined as percent coefficient of variation $(\% \mathrm{CV})$; target $\leq 36 \%$
13 days

$99.9 \%$

$173 \mathrm{mg} / \mathrm{dL}$

$7.6 \%$

$49.5 \%$
TIME IN RANGES

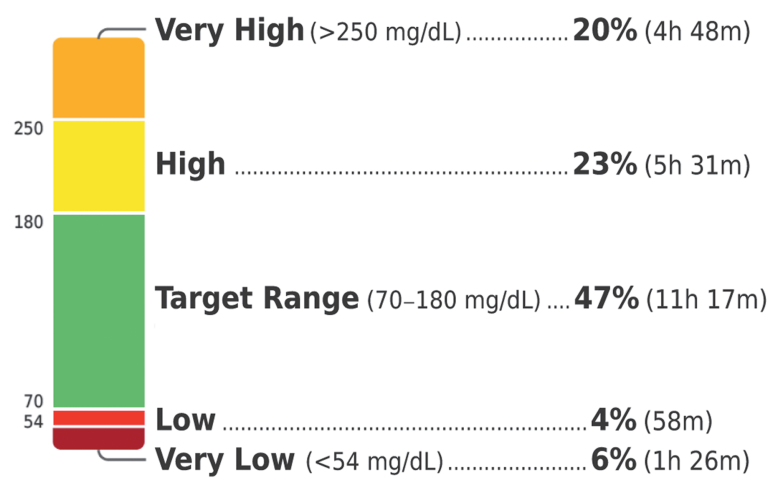

\section{AMBULATORY GLUCOSE PROFILE (AGP)}

AGP is a summary of glucose values from the report period, with median $(50 \%)$ and other percentiles shown as if occurring in a single day.

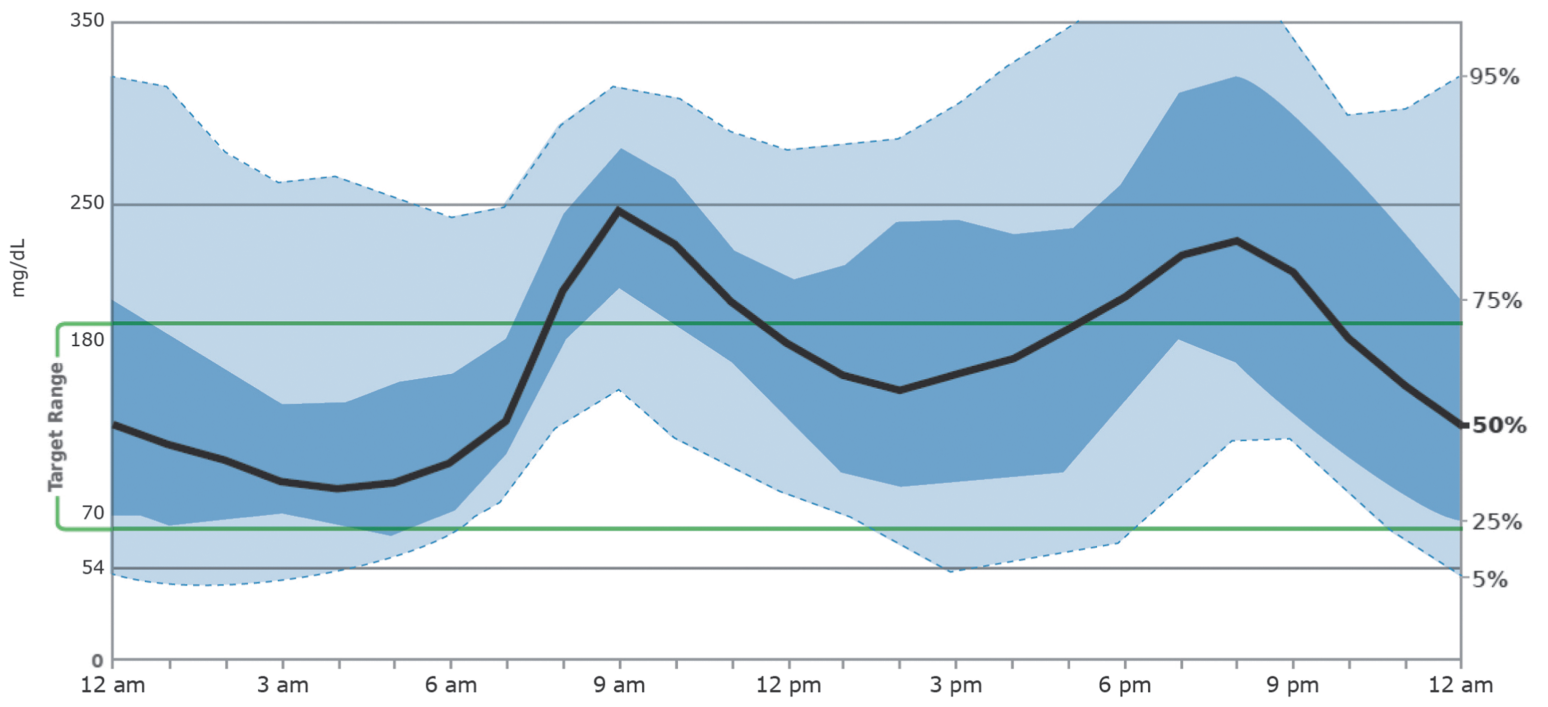

\section{DAILY GLUCOSE PROFILES}

Monday
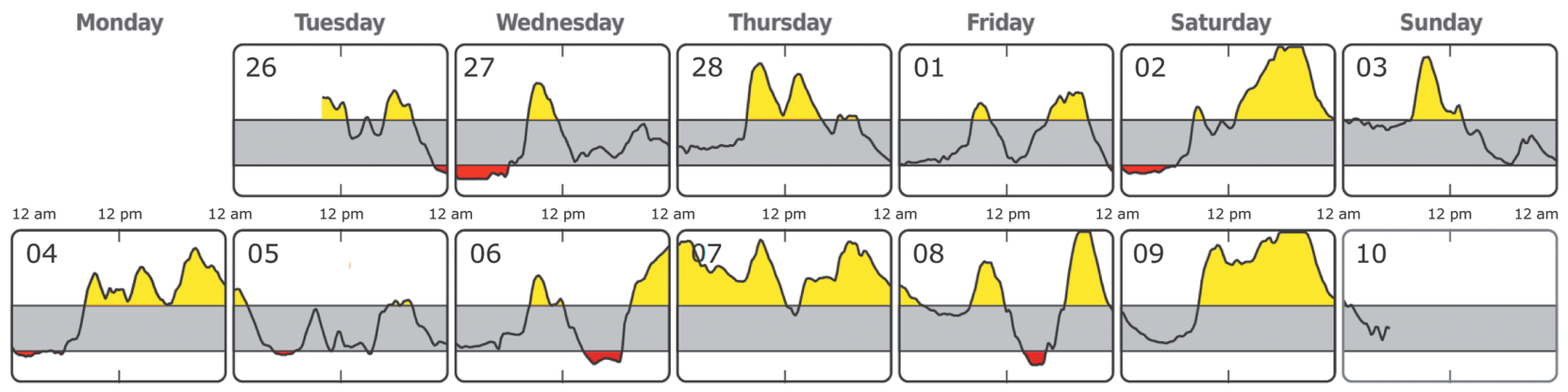

Each daily profile represents a midnight-to-midnight period.

(0) 2019 International Diabetes Center at Park Nicollet

captūrAGP

FIG. 1. Ambulatory glucose profile. The AGP provides graphical and statistical representations of a patient's daily glucose patterns and key characteristics of glycemic control (e.g., time in range and glycemic variability). AGP, ambulatory glucose profile. 
- Look at the daily views to double-check patterns of low glucose and see if they are clustered on weekends or special activity days.

5. Look for patterns of high glucose values.

- Remember to ask how many times per week a medication may have been forgotten or if meal-time insulin was actually taken before meals.

- Look at what was marked as usual meal times and discuss whether high values are usually before or after mealtimes.

- Ask about usual differences in weekend versus weekday times for waking, meals, and bedtime.

- Look at the separate printout of daily views to double-check patterns of high glucose and see if they are clustered on weekends or special activity days.

6. Discuss areas where darker blue (50\% of values) or lighter blue ( $90 \%$ of values) shaded areas are very wide (corresponding to high glucose variability).

- Can the patient do anything to reduce glycemic variability by adjusting the timing or amount of food intake, refining their carbohydrate counting, adjusting the timing of medications, or exercise and/or reducing stress?

- Match food and exercise log or electronic data, if available, with AGP.

7. Compare current AGP and CGM metrics to those from last visit (or contact), if available, and discuss progress.

8. Agree on an action plan consisting of one or two specific recommendations:

- Treat hypoglycemia first.

- When treating a pattern of hyperglycemia, look at least $12-18 \mathrm{~h}$ past the time of the hyperglycemia you plan to treat. If the darker blue ( $25 \%$ of values) or gray ( $5 \%$ of values) curves are touching the $70 \mathrm{mg} / \mathrm{dL}$ line or lower, be very cautious or hold off on correcting hyperglycemia until the hypoglycemia is addressed.

9. Print a copy of the marked-up AGP for the patient and store a PDF of the AGP into the EMR, if possible, or at least copy (snip) and paste the AGP into the EMR progress note.

Our institution is currently using this interpretation plan to optimize use of AGP, both for shared decision-making in a clinic-based and team management-based environment, and also by individuals with T1D and T2D new to the concept of viewing glucose data and AGP reports. Acceptance by our care teams of AGP data use for shared decision-making has been high.

\section{Clinical Use of CGM and AGP in Diabetes Management}

Advances in technology have significantly decreased the cost of CGM. Technical improvements have increased simplicity of use, allowed the use of CGM technology without calibration, and there is less interference by acetaminophen and other therapeutic agents. These improvements have increased CGM uptake in the management of T1D both in pediatric and adult populations and have allowed movement of CGM technology into primary care, where T2D is often managed. As the use of CGM technology in broader populations becomes established, the AGP will become increasingly important in allowing rapid and intuitive interpretation of glycemic patterns.

CGM systems can be used to help optimize diabetes management by both retrospective review of glucose patterns and by teaching CGM users to use the real time CGM glucose data to adjust diet and exercise habits or premeal insulin doses. ${ }^{53}$ Retrospective analysis of CGM data using AGP, from real-time or masked CGM data, presents a more complete picture of glycemic management, providing critical metrics such as TIR, allowing evaluation of glycemic variability, and displaying glycemic patterns. This information guides therapeutic decision-making and enhances patient understanding and engagement in adjusting their behaviors and lifestyle. This leads to more discussion and collaborative patient-clinician interactions than could have been previously achieved by relying on $\mathrm{HbA} 1 \mathrm{c}$ alone or by using realtime CGM alone.

In endocrinology and specialty practices, AGP allows for analysis of CGM data in combination with insulin pump data. AGP pump and closed loop views have been developed and can be reviewed on AGPreport.org. The value of CGM in T2D has been shown in individuals on MDI therapy. ${ }^{6,11}$ As in T1D, individuals with T2D on intensive insulin regimens can benefit from the use and availability of CGM for glycemic monitoring.

Studies have also suggested a role for CGM in managing individuals with $\mathrm{T} 2 \mathrm{D}$ not on intensive insulin regimens. Vigersky et al. showed short-term improvement in HbAlc values in individuals with T2D not on prandial insulin, using intermittent real-time CGM, over a 12-week study period, with persistence of $\mathrm{HbA} 1 \mathrm{c}$ benefit at 52 -week follow-up. ${ }^{54}$ An older study has suggested a role for CGM in reinforcing lifestyle interventions and physical activity. ${ }^{55}$

The increasing availability and use of CGM technology across these broader populations of individuals with diabetes brings new challenges both in terms of implementation of CGM technology and also interpretation of data. While we have attempted to address interpretation of retrospective CGM data through use of AGP presentation and through our "9 Step" training guide, availability of AGP data at the time of clinical interactions in primary care remains an obstacle.

Barriers to access to AGP data outside of specialty practices include issues with information technology systems, including organizational firewalls, physical constraints (need for cables for hardwire downloads, or Bluetooth enabled technology for wireless upload) both on patient and care system levels, and time constraints in a clinic-based setting. These barriers are magnified as CGM systems are adopted more broadly in primary care networks and health care systems.

In our clinic practice, we have addressed these barriers through multiple strategies. As the availability and use of cloud-based data platforms expand, we have developed multiple workflows to facilitate access to data. This includes cloud-based data retrieval for remote monitoring and a decrease in the need for clinic visits. When cloud-based data are not available, our institution has worked to create work flows and nursing processes, including innovative capabilities to download data in clinic waiting areas before visits. 
The standardized AGP report and the ability to easily access the AGP optimizes the likelihood that glycemic data will be available to the clinician and patient to improve the management of diabetes in multiple settings. Building the technological and human resource-based systems to make AGP data available to clinicians and patients as CGM technology expands into the broader T2D population will be a key to leveraging this technology to improve the lives of individuals with T2D.

\section{Summary}

Use of CGM is recognized as a valuable component of diabetes self-management and is now considered a standard of care for individuals with diabetes who are treated with intensive insulin therapy. ${ }^{16-18,56}$ Numerous studies have demonstrated the clinical benefits of CGM use in individuals with T1D and T2D who are treated with MDI or insulin pumps. $^{3-11}$

The AGP report displays the key CGM metrics agreed upon by numerous CGM consensus reports which inform clinicians and patients if additional glucose management changes are needed. In addition, the AGP displays a 2-week consolidated glucose profile and daily glucose views to help determine what management changes would be most appropriate. The AGP further supports the clinical utility of CGM by replacing device-specific reports with a standardized presentation of the data that may result in faster, more accurate interpretation while minimizing the need for multiple software programs and connecting cables. Further development of decision support tools and management recommendations is underway to assist providers and patients in maximizing the benefits of using CGM.

\section{Acknowledgments}

We acknowledge Jane Norstrom MA, Deborah Mullen, $\mathrm{PhD}$, Roger S. Mazze, PhD, Janet L. Davidson, RN, BSN, CDE, Ellie Strock, ANP-BC, CDE, David Wesley, and Joan Bissen for their leadership in AGP design, training, implementation, and partnership development. We also thank our collaborating clinical partners in Park Nicollet and HealthPartners Pediatric and Adult Endocrinology and Primary Care clinics. We would also like to acknowledge Park Nicollet Foundation's support of the IDC's technology implementation work and the AGP development grant from The Leona M. and Harry B. Helmsley Charitable Trust. The authors also wish to thank Christopher G. Parkin (CGParkin Communications, Inc., Henderson, NV) for editorial assistance. Funding: Roche Diabetes Care provided funding for the development of this article.

\section{Author Disclosure Statement}

M.L.J. has received research support and/or consulted for Abbott Diabetes Care, Dexcom, Johnson \& Johnson, Medtronic, Novo Nordisk, Roche, and Sanofi. Her employer, nonprofit International Diabetes Center (IDC)/HealthPartners Institute/Park Nicollet, contracts for her services and she receives no personal income from these activities. T.W.M. has received research support from Abbott Diabetes Care, Dexcom, Medtronic, Novo Nordisk, and Lilly. His employer, nonprofit IDC/HealthPartners Institute/Park Nicollet, con- tracts for his services and he receives no personal income from these activities. A.B.C. has received research support and/or consulted for Abbott Diabetes Care, Dexcom, Medtronic, Novo Nordisk, and Roche Diabetes Care. Her employer, nonprofit IDC/HealthPartners Institute/Park Nicollet, contracts for her services and she receives no personal income from these activities. A.L.C. has received research support, consulted or has been on the scientific advisory board for Abbott Diabetes Care, Dexcom, Insulet, Medtronic, Novo Nordisk, Roche, and Sanofi. His employer, nonprofit IDC/HealthPartners Institute/Health Partners, contracts for his services, and he receives no personal income from these activities. R.M.B. has received research support, consulted or has been on the scientific advisory board for Abbott Diabetes Care, CeQur, Dexcom, Hygieia, Johnson \& Johnson, Lilly, Medtronic, Novo Nordisk, Onduo, Roche, Sanofi, and United Healthcare. His technology research is partly funded by NIDDK (NIH grant DK108611). His employer, nonprofit IDC/HealthPartners Institute/Park Nicollet, contracts for his services, and he receives no personal income from these activities. Any contractual proceeds related to the patent and licensing agreements regarding the AGP are not paid to the authors. Proceeds are directed to the nonprofit IDC/HealthPartners Institute and used to support operational and development costs.

\section{References}

1. Aleppo G, Laffel LM, Ahmann AJ, et al.: Practical approach to using trend arrows on the Dexcom G5 CGM system for the management of adults with diabetes. J Endocr Soc 2017;1:1445-1460.

2. Kudva YC, Ahmann AJ, Bergenstal RM, et al.: Approach to using trend arrows in the FreeStyle Libre Flash Glucose Monitoring Systems in adults. J Endocr Soc 2018;2:1320 1337.

3. Lind M, Polonsky W, Hirsch IB: Continuous glucose monitoring vs conventional therapy for glycemic control in adults with type 1 diabetes treated with multiple daily insulin injections: the GOLD randomized clinical trial. JAMA 2017;317:379-387.

4. Aleppo G, Ruedy KJ, Riddlesworth TD, et al.: REPLACEBG: a randomized trial comparing continuous glucose monitoring with and without routine blood glucose monitoring in adults with well-controlled type 1 diabetes. Diabetes Care 2017;40:538-545.

5. Beck RW, Riddlesworth T, Ruedy K, et al.: Effect of continuous glucose monitoring on glycemic control in adults with type 1 diabetes using insulin injections: the DIAMOND randomized clinical trial. JAMA 2017;317: 371-378.

6. Beck RW, Riddlesworth TD, Ruedy K, et al.: Continuous glucose monitoring versus usual care in patients with type 2 diabetes receiving multiple daily insulin injections: a randomized trial. Ann Intern Med 2017;167:365-374.

7. Beck RW, Riddlesworth TD, Ruedy KJ, et al.: Effect of initiating use of an insulin pump in adults with type 1 diabetes using multiple daily insulin injections and continuous glucose monitoring (DIAMOND): a multicentre, randomised controlled trial. Lancet Diabetes Endocrinol 2017;5:700-708.

8. Šoupal J, Petruželková L, Flekač M, et al.: Comparison of different treatment modalities for type 1 diabetes, including sensor-augmented insulin regimens, in 52 weeks of 
follow-up: a COMISAIR study. Diabetes Technol Ther 2016;18:532-538.

9. van Beers CA, DeVries JH, Kleijer SJ, et al.: Continuous glucose monitoring for patients with type 1 diabetes and impaired awareness of hypoglycaemia (IN CONTROL): a randomised, open-label, crossover trial. Lancet Diabetes Endocrinol 2016;4:893-902.

10. Bolinder J, Antuna R, Geelhoed-Duijvestijn P, et al.: Novel glucose-sensing technology and hypoglycemia in type 1 diabetes: a multicentre, non-masked, randomised controlled trial. Lancet 2016;388:2254-2263.

11. Haak T, Hanaire H, Ajjan R, et al.: Flash glucose-sensing technology as a replacement for blood glucose monitoring for the management of insulin-treated type 2 diabetes: a multicenter, open-label randomized controlled trial. Diabetes Ther 2017;8:55-73.

12. Choudhary P, Olsen BS, Conget I, et al.: Hypoglycemia prevention and user acceptance of an insulin pump system with predictive low glucose management. Diabetes Technol Ther 2016;18:288-291.

13. Bergenstal RM, Klonoff DC, Garg SK, et al.: Thresholdbased insulin-pump interruption for reduction of hypoglycemia. N Engl J Med 2013;369:224-232.

14. Bergenstal RM, Garg S, Weinzimer SA, et al.: Safety of a hybrid closed-loop insulin delivery system in patients with type 1 diabetes. JAMA 2016;316:1407-1408.

15. Garg SK, Weinzimer SA, Tamborlane WV, et al.: Glucose outcomes with the in-home use of a hybrid closed-loop insulin delivery system in adolescents and adults with type 1 diabetes. Diabetes Technol Ther 2017;19:155-163.

16. American Diabetes Association: 7. Diabetes technology: Standards of Medical Care-2019. Diabetes Care 2019;42 (Suppl 1):S71-S80.

17. Fonseca VA, Grunberger G, Anhalt H, et al.: for the Consensus Conference Writing Committee. Continuous Glucose Monitoring: a consensus conference of the American Association of Clinical Endocrinologists and American College of Endocrinology. Endocr Pract 2016;22:10081021.

18. Danne T, Nimri R, Battelino $\mathrm{T}$, et al.: International consensus on use of continuous glucose monitoring. Diabetes Care 2017;40:1631-1640.

19. Mullen DM, Bergenstal R, Criego A, et al.: Time savings using a standardized glucose reporting system and ambulatory glucose profile. J Diabetes Sci Technol 2018;12:614621.

20. National Diabetes Information Clearinghouse (NDIC): Sickle cell trait and other hemoglobinopathies and diabetes: important information for providers [Internet]. http:// diabetes.niddk.nih.gov/dm/pubs/hemovari-A1C/index.aspx (accessed January 12, 2018).

21. Bry L, Chen PC, Sacks DB: Effects of hemoglobin variants and chemically modified derivatives on assays for glycohemoglobin. Clin Chem 2001;47:153-163.

22. Ford ES, Cowie CC, Li C, et al.: Iron-deficiency anemia, non-iron-deficiency anemia and $\mathrm{HbA} 1 \mathrm{c}$ among adults in the US. J Diabetes 2011;3:67-73.

23. Nielsen LR, Ekbom P, Damm P, et al.: HbA1c levels are significantly lower in early and late pregnancy. Diabetes Care 2005;27:1200-1201.

24. Beck RW, Connor CG, Mullen DM, et al.: The fallacy of average: how using HbA1c alone to assess glycemic control can be misleading. Diabetes Care 2017;40:994-999.
25. Rodbard D: Interpretation of continuous glucose monitoring data: glycemic variability and quality of glycemic control. Diabetes Technol Ther 2009;11(Suppl 1):S55-S67.

26. Lu J, Ma X, Zhou J, et al.: Association of time in range, as assessed by continuous glucose monitoring, with diabetic retinopathy in type 2 diabetes. Diabetes Care 2018;41: 2370-2376.

27. Beck RW, Bergenstal RM, Riddlesworth TD, et al.: Validation of time in range as an outcome measure for diabetes clinical trials. Diabetes Care 2019;42:400-405.

28. Brod M, Christensen T, Thomsen TL, Bushnell DM: The impact of non-severe hypoglycemic events on work productivity and diabetes management. Value Health 2011;14:665-671.

29. Brod M, Rana A, Barnett AH: Impact of self-treated hypoglycaemia in type 2 diabetes: a multinational survey in patients and physicians. Curr Med Res Opin 2012;28:1947-1958.

30. Seaquist ER, Anderson J, Childs B, et al.: Hypoglycemia and diabetes: a report of a workgroup of the American Diabetes Association and the Endocrine Society. Diabetes Care 2013;36:1384-1395.

31. International Hypoglycaemia Study Group: Glucose concentrations of less than $3.0 \mathrm{mmol} / \mathrm{L}(54 \mathrm{mg} / \mathrm{dL})$ should be reported in clinical trials: a joint position statement of the American Diabetes Association and the European Association for the Study of Diabetes. Diabetes Care 2017;40:155-157.

32. Novodvorsky P, Bernjak A, Chow E, et al.: Diurnal differences in risk of cardiac arrhythmias during spontaneous hypoglycemia in young people with type 1 diabetes. Diabetes Care 2017;40:655-662.

33. Beck RW, Bergenstal RM, Riddlesworth TD, Kollman C: The association of biochemical hypoglycemia with the subsequent risk of a severe hypoglycemic event: analysis of the DCCT data set. Diabetes Technol Ther 2019;21:1-5.

34. Stone MP, Agrawal P, Chen X, Liu M, Shin J, Cordero TL, Kaufman FR: Retrospective analysis of 3-month real-world glucose data after the MiniMed 670G system commercial launch. Diabetes Technol Ther 2018;20(10):689-692.

35. White NH, Skor DA, Cryer PE, et al.: Identification of type I diabetic patients at increased risk for hypoglycemia during intensive therapy. N Engl J Med 1983;308:485-491.

36. Cryer PE, Gerich JE: Glucose counterregulation, hypoglycemia, and intensive insulin therapy in diabetes mellitus. N Engl J Med 1985;313:232-241.

37. Amiel SA, Tamborlane WV, Simonson DC, Sherwin RS: Defective glucose counterregulation after strict glycemic control of insulin-dependent diabetes mellitus. N Engl J Med 1987;316:1376-1383.

38. Rodbard D: Hypo- and hyperglycemia in relation to the mean, standard deviation, coefficient of variation, and nature of the glucose distribution. Diabetes Technol Ther 2012;14:868-876.

39. Cox DJ, Kovatchev BP, Julian DM, et al.: Frequency of severe hypoglycemia in insulin dependent diabetes mellitus can be predicted from self-monitoring blood glucose data. J Clin Endocrinol Metab 1994;79:1659-1662.

40. Qu Y, Jacober SJ, Zhang Q, et al.: Rate of hypoglycemia in insulin-treated patients with type 2 diabetes can be predicted from glycemic variability data. Diabetes Technol Ther 2012;14:1008-1012.

41. El-Laboudi AH, Godsland IF, Johnston DG, Oliver NS: Measures of glycemic variability in type 1 diabetes and the effect of real-time continuous glucose monitoring. Diabetes Technol Ther 2016;18:806-812. 
42. Monnier L, Colette C, Wojtusciszyn A, et al.: Toward defining the threshold between low and high glucose variability in diabetes. Diabetes Care 2017;40:832-838.

43. Xing D, Kollman C, Beck RW, et al.: Optimal sampling intervals to assess long-term glycemic control using continuous glucose monitoring. Diabetes Technol Ther 2011; 13:351-358.

44. Riddlesworth TD, Beck RW, Gal RL, et al.: Optimal sampling duration for continuous glucose monitoring to determine long-term glycemic control. Diabetes Technol Ther 2018;20:314-316.

45. Bergenstal RM, Beck RW, Close KL, et al.: Glucose Management Indicator (GMI): a new term for estimating A1C from continuous glucose monitoring. Diabetes Care 2018;41:2275-2280.

46. Pluchino KM, Wu Y, Silk AD, et al.: Comment on Bergenstal et al. Glucose management indicator (GMI): a new term for estimating A1C from continuous glucose monitoring. Diabetes Care 2018;41:2275-2280.

47. Bergenstal RM, Ahmann AJ, Bailey T, et al.: Recommendations for standardizing glucose reporting and analysis to optimize clinical decision making in diabetes: the Ambulatory Glucose Profile (AGP). Diabetes Technol Ther 2013;15:198-211.

48. Fonseca V, Grunberger G: Standard Glucose Reporting: Follow-up to the February 2016 AACE CGM Consensus Conference. Endocr Pract 2017;23:629-632.

49. International Diabetes Center: AGP-Ambulatory Glucose Profile: AGP reports. Www.agpreport.org/agp/agpreports (accessed April 22, 2018).

50. Mazze RS, Lucido D, Langer O, et al.: Ambulatory glucose profile: representation of verified self-monitored blood glucose data. Diabetes Care 1987;10:111-117.
51. Rodbard D: Display of glucose distributions by date, time of day, and day of week: new and improved methods. J Diabetes Sci Technol 2009;3:1388-1394.

52. Rodbard D: Glucose variability: a review of clinical applications and research developments. Diabetes Technol Ther 2018;20(S2):S25-S215.

53. Kruger DF, Edelman SV, Hinnen DA, Parkin CG: Reference guide for integrating continuous glucose monitoring into clinical practice. Diabetes Educ 2019;45(suppl 1): $3 \mathrm{~S}-20 \mathrm{~S}$.

54. Vigersky RA, Fonda SJ, Chellappa M, et al.: Short- and long-term effects of real-time continuous glucose monitoring in patients with type 2 diabetes. Diabetes Care 2012; 35:32-38.

55. Allen NA, Fain JA, Braun B, Chipkin SR: Continuous glucose monitoring counseling improves physical activity behaviors of individuals with type 2 diabetes: a randomized clinical trial. Diabetes Res Clin Pract 2008;80: 371-379.

56. Borot S, Benhamou PY, Atlan C, et al.: Practical implementation, education and interpretation guidelines for continuous glucose monitoring: a French position statement. Diabetes Metab 2017;44:61-72.

Address correspondence to: Mary L. Johnson, BS, RN, CDE International Diabetes Center at Park Nicollet 3800 Park Nicollet Boulevard Minneapolis, MN 55416

E-mail: mary.1.johnson@parknicollet.com 